\title{
ISOLATION OF ETHYLCYCLOHEXANE FROM A
} MIDCONTINENT PETROLEUM ${ }^{1}$

\author{
By Frank W. Rose, Jr., ${ }^{2}$ and Joseph D. White ${ }^{2}$
}

\begin{abstract}
Fractionation of that portion of a midcontinent petroleum which normally boils between 131 and $133^{\circ} \mathrm{C}$ has resulted in the isolation for the first time of a naphthene identified as ethylcyclohexane. The methods employed in its separation are systematic fractional distillation, distillation with glacial acetic acid, and fractional crystallization from a solution in liquid propane and methane.

Ethylcyclohexane of very high purity has been synthesized and compared with that isolated from petroleum with respect to the following physical properties: Boiling point, freezing point, refractive index, density, molecular weight, and infrared absorption spectrum. The critical solution temperature in aniline and the carbon-hydrogen ratio of the ethylcyclohexane from petroleum have been determined. The purity of the isolated material is estimated to be about 95 mole percent. The total content in petroleum has not been determined but does not exceed 0.1 percent.
\end{abstract}

\section{CONTENTS}

Introduction

II. Procedure and results

1. Preliminary fractionation

2. Preliminary study of the fraction

3 . Crystallization of the distillation fractions

4. Further separation of the component $\ldots$

III. Properties and identification of the isolated ethylcyclohexane

1. Preparation and purification of the synthetic hydrocarbon

2. Properites of the material isolated from petroleum

\section{INTRODUCTION}

In the literature concerning the composition of petroleum one finds the occurrence of many hydrocarbons established by speculation rather than by isolation. Thus, the only reported suspicion of the presence of ethylcyclohexane in petroleum is based on trends in certain physical properties of a distillate. In an investigation of Roumanian petroleum freed of aromatic hydrocarbons, Poni, ${ }^{3}$ after repeatedly distilling the oil in a fractionating column, observed slight maxima at 132 to $134^{\circ} \mathrm{C}$ in the curves obtained by plotting the volumes and densities of the fractions against their boiling points. $\mathrm{He}$ inferred the presence of ethylcyclohexane from these maxima.

In the present work, no evidence ${ }^{4}$ of a compound boiling at 131 to $132^{\circ} \mathrm{C}$ was apparent after a preliminary distillation, an extraction 1 Financial assistance for this work has been received from the research fund of the American Petroleum
Institute. This work is part of Project 6, The Separation, Identification, and Determination of the Constituents of Petroleum.

2 Research Associate at the National Bureau of Standards, representing the American Petroleum Institute.

3 P. Poni, Ann. Scient. de l'Univ. de Jassy, 2, 74 (1903)

J. D. White and F. W. Rose, Jr., BS J. Research 9, 712 (1932) RP501. See figure 1, graph II. 
to remove the bulk of the aromatic constituents, and a subsequent systematic distillation in a 30 -plate fractionating column. However, with continued redistillation, latterly in more efficient columns, concentration of a naphthene was noted.

The fraction of oil boiling normally from 131 to $133^{\circ} \mathrm{C}$, upon extended application of physical methods of separation, yielded the naphthene, ethylcyclohexane.

\section{PROCEDURE AND RESULTS}

\section{PRELIMINARY FRACTIONATION}

The source of the petroleum for this investigation has been described elsewhere. ${ }^{5}$ Under the direction of S. T. Schicktanz the naphtha fraction had been subjected to 6 systematic distillations (3 at atmospheric pressure followed by 3 at $215 \mathrm{~mm} \mathrm{Hg}$ ). The distillations were carried out in Pyrex glass bubblejcap columns, using a reflux ratio of $10: 1$ and a rate of about $1 \mathrm{ml}$ per minute, collecting the distillate in $0.5^{\circ}$ cuts. After the first and second distillations, the material had been extracted with liquid sulphur dioxide to remove the bulk of the aromatic hydrocarbons.

The distribution of volume with boiling point at the end of the sixth systematic distillation has been shown in an earlier paper. ${ }^{6}$ Cuts having boiling points below $90^{\circ} \mathrm{C}$ at $215 \mathrm{~mm} \mathrm{Hg}\left(132^{\circ} \mathrm{C}\right.$ at $760 \mathrm{~mm} \mathrm{Hg}$ ) had been combined with cuts of the same boiling point obtained as a result of distilling mother liquors from the crystallization of $n$-octane. ${ }^{7}$ The combined material had been systematically distilled once at atmospheric pressure and again extracted with liquid sulphur dioxide. The immiscible portion, together with the fractions boiling normally at 132 to $133^{\circ} \mathrm{C}$, had been treated with concentrated sulphuric acid, and redistilled at atmospheric pressure. Meanwhile, the use of more efficient columns packed with jeweler's locket chain to distil fractions containing isononanes (boiling point ca. $135^{\circ} \mathrm{C}$ ) had resulted in the separation of a portion of that stock as a lowerboiling fraction.

A graph showing the boiling-point-volume and boiling-pointrefractive-index relations of all the distillates accumulating in the range 129 to $135^{\circ} \mathrm{C}$, is given in figure 1 . The salient features of the data illustrated are: (1) the volume maximum occurring at $131.5^{\circ} \mathrm{C}$; (2) the proximity of this volume maximum to that of the refractive index. Hence, it may be concluded that one or more compounds, naphthenic in nature, are the major constituents in this range. The total volume of oil distilling in the interval 129.5 to $134.5^{\circ} \mathrm{C}$ amounts to only 5.5 liters, approximately 75 percent of which is naphthenic. It may be noted that this is from 600 gallons of the original crude oil. The broadness of the peak, together with the theoretical possibility of several octonaphthenes boiling in this range having either cyclopentane or cyclohexane rings, points to the presence of more than one hydrocarbon.

5 E. W. Washburn, J. H. Bruun, and M. M. Hicks, BS J. Research 2, 469 (1929) RP45.

6 J. D. White and F. W. Rose, J. Research NBS 13, 801 (1934) RP745, figure 2.

7 R.T. Leslie and S. T. Schicktanz, BS J. Research 6, 377-386 (1931) RP282. 


\section{PRELIMINARY STUDY OF THE FRACTION}

Inasmuch as the larger of two portions comprising the available oil of this range had not been distilled in the more efficient locketchain columns, this material, together with appropriate fractions resulting from the isononane distillation, was given such a fractionation. Owing to the paucity of material, extensive combination of fractions having the same boiling point and refractive index was often necessary to produce charges of sufficient size. As a result of this distillation, there was separated approximately $1,800 \mathrm{ml}$ of

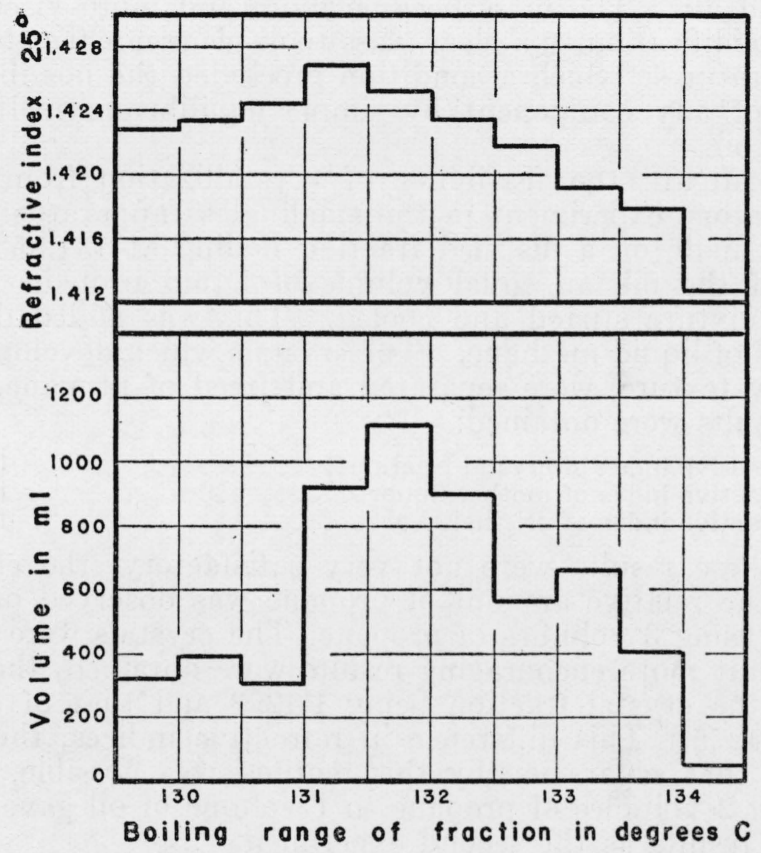

Figure 1.-Volume distribution and refractive indices with respect to boiling range $(760 \mathrm{~mm} \mathrm{Hg})$ at start of work.

oil boiling principally at $131.8^{\circ} \mathrm{C}$, and having a refractive index of $1.4275,{ }^{8}$ but covering the range of 131.5 to $132.5^{\circ} \mathrm{C}$ in boiling point and 1.4265 to 1.4285 in refractive index.

To ascertain whether all aromatics had been removed by the concentrated sulfuric acid, a sample fraction was treated with the usual nitrating acid. ${ }^{9}$ So much heat was generated that cooling was necessary and nitrous fumes were evolved. The unattacked oil was neutralized and distilled from sodium. The acid layer gave a reddish-brown oil when poured upon ice. This is possibly indicative of ethylbenzene. The effect of the nitration on the refractive index was as follows:

Original oil

Oil after treatment

Reduction by nitration.

${ }^{8}$ All refractive indices in this paper are for $n_{\mathrm{D}}^{25}$ unless otherwise noted.

○. H. Bruun, R. T. Leslie, and S. T. Schicktanz, BS J. Research 6, 364 (1931) RP280. 
In view of the oxidation shown by the presence of nitrous fumes, the change in refractive index could be attributed to the decomposition of the naphthene. If it is due to the removal of aromatics, a concentration of about 2 mole percent of the latter is indicated. It was deemed inadvisable to attempt to remove these small residual amounts of aromatics by nitration owing to the vigor of the reaction and to the possibility of serious loss of the naphthene.

A selected fraction of the oil, having a refractive index of 1.4270 and a boiling point of $131.5^{\circ} \mathrm{C}$, was placed in a dewar tube equipped with a 5 -junction thermocouple and a mechanical stirrer, and cooled with liquid air. The mass became more and more viscous until a gradual solidification to a clear glass took place not far above liquidair temperatures. Such a condition precluded the possibility of the isolation of any component by simple equilibrium melting of the undiluted oil.

To investigate the feasibility of crystallization from a solvent, an exploratory experiment in the small glass apparatus of Leslie ${ }^{10}$ was then made on a distilled fraction boiling at $131.85^{\circ} \mathrm{C}$. To a volume of the oil, an equal volume of liquid propane was added and the mixture stirred and cooled. This was added dropwise to 2 volumes of liquid methane. The crystals which developed, though of a pasty texture, were separated and freed of propane. The following results were obtained:

Refractive index of crystal fraction
Refractive index of mother liquor
Refractive index of original

Since these results were not very satisfactory, the effect of increasing the relative amount of propane was observed on the same material, using 3 volumes of propane. The crystals were still rather gummy, but more encouraging results were obtained, the refractive index of the crystal fraction being 1.4293 and that of the mother liquor, 1.4275. This difference in refractive indices, though small, indicated that separation by this method was possible. A similar trial using 2 volumes of propane to 1 volume of oil gave essentially the same results as the second experiment.

\section{CRYSTALLIZATION OF THE DISTILLATION FRACTIONS}

Since crystallization in the manner outlined above was the only method which gave promise of eventual separation of the pure component, all fractions amenable to this treatment (the $1,800 \mathrm{ml}$ of material previously noted) were crystallized in the large metal centrifuge as described by Leslie. ${ }^{10}$ Typical data are given in table 1.

The technic of these crystallizations requires experience and judgment and no set rules can be given for all fractions. The proportions of solvent and solute were varied according to the judgment of the operator; most frequently, 2 volumes of propane, 1 volume of oil, and 2 volumes of methane were used.

The fractions having a refractive index below 1.4260 gave poor results generally, and few attempts were made to crystallize them. Possibly significant is the fact that better separation, as judged by refractive index, occurred with cuts having boiling points above $131.7^{\circ}$. This might be interpreted as evidence for a second naph-

\footnotetext{
${ }_{10}$ R. T. Leslie, BS J. Research 10, 609-618 (1933) RP552.
} 
thene boiling at a lower temperature than the one isolated. If this were true, the mother liquors of the lower-boiling fractions would consist principally of a eutectic of the two naphthenes, whereas the higher-boiling cuts would contain mainly paraffinic material as an impurity.

TABLE 1.-Typical results of crystallization from liquid propane and methane 1

\begin{tabular}{|c|c|c|c|c|c|}
\hline \multicolumn{2}{|c|}{ Original fraction } & \multicolumn{2}{|c|}{ Crystal fraction } & \multicolumn{2}{|c|}{ Mother liquor } \\
\hline Boiling range & $n_{\mathrm{D}}^{25}$ & Volume & $n_{\mathrm{D}}^{25}$ & Volume & $n_{\mathrm{D}}^{23}$ \\
\hline${ }^{\circ} \mathrm{C}$ & & $\mathrm{ml}$ & & $\mathrm{ml}$ & \\
\hline $131.8-$ & 1.4287 & 34 & 1.4289 & 17 & 1. 4248 \\
\hline $131.7_{5}-$ & 1. 42 & 29 & 1.4 & 29 & 1.4263 \\
\hline $131.6-$ & 1.42 & 19 & 1. 4 & 30 & 1. 4270 \\
\hline $131.7-$ & 1. 42 & 49 & 1.4 & 39 & 1.4 \\
\hline 132.0 - & 1. 4277 & 40 & 1.4 & 23 & 1. 4247 \\
\hline $132.0-$ & 1.42 & 35 & 1.4 & 18 & 1.4236 \\
\hline $131.3-$ & 1.4263 & 47 & 1.4265 & 8 & 1. 4245 \\
\hline $131.4-$ & 1.4276 & 75 & 1.42 & 7 & 1.4251 \\
\hline 132.5 & 1.42 & 6 & 1. 4252 & 42 & 1.4246 \\
\hline $131.9-132.5$ & 1.4266 & 30 & 1.4280 & 22 & 1.4235 \\
\hline
\end{tabular}

1 These fractions had not been treated with silica gel and the refractive indices are too high by about 0.001 .

\section{FURTHER SEPARATION OF THE COMPONENT}

At this juncture several new developments were utilized. First, selective adsorption by silica gel was used to remove the confusing and troublesome residual amounts of aromatic compounds. Second, fractions only moderately concentrated in the naphthene were distilled with glacial acetic acid to yield more fractions susceptible of crystallization. Third, a still of small capacity made further distillation of certain fractions feasible.

With the apparatus and technic described by Mair and White, ${ }^{11}$ the separation with silica gel was continued until all the material was freed of aromatic compounds. In the case of the distillates, the change in refractive index resulting from this treatment varied quite widely, being usually about 0.0010 to 0.0015 , but in some cases, notably distillation residues, differences as great as 0.0045 were attained. The refractive indices of the crystal fractions thus far obtained were lowered about the same amount as were those of the mother liquors; i. e., 0.0010 to 0.0015 , which indicated that the aromatic hydrocarbons had not been completely removed by crystallization.

After this treatment, the fractions of the distillate that did not crystallize were distilled in a 30 -plate fractionating column with glacial acetic acid. ${ }^{12}$ By this means, an additional concentration of naphthenes was effected, proper cuts being combined as far as possible.

In order to concentrate a suspected second naphthene into cuts somewhat removed from those containing the bulk of the main component, the fractions resulting from the acetic acid process were systematically distilled in a spiral column coated with carborundum and equipped with a vacuum jacket and reflux regulator. In the course of this distillation, the mother liquors from the crystallization

11 B. J. Mair and J. D. White, J. Research NBS 15, 51 (1935) RP809.

12 The process of distillation with glacial acetic acid will be described in a fortheoming paper by $\mathrm{S}$. T. Schicktanz. It operates through the formation of minimum azeotropic mixtures and gives a separation of material in certain cases which would fractionate very slowly when distilled as undiluted oil. 
from liquid methane were combined with the major portion of the distillate, as were certain fractions resulting from the systematic distillation of lower boiling fractions, as well as the nonaromatic portion of (1) the oil adsorbed by silica gel and (2) some residues from the isolation of ethylbenzene.

Various portions of oil accumulating as a result of this technic were crystallized from methane with the following results: (1) fractions having a refractive index below 1.425 showed no separation on crystallization; (2) fractions having a refractive index above 1.425, but boiling at a temperature lower than $131.5^{\circ} \mathrm{C}$, gave little apparent separation as judged by refractive index; (3) crystallization of a cut with boiling range 130.9 to $131.0^{\circ} \mathrm{C}, n_{\mathrm{D}}^{25}=1.4255$, gave little separation, but the crystal fraction in this case boiled at a lower temperature than the mother liquor; (4) the boiling points of all other crystal fractions rose with increasing purity (see table 2); (5) the mother liquors on redistillation boiled for the most part at temperatures below $131.5^{\circ} \mathrm{C}$.

After removing the main component as far as possible by crystallization from all material available, the crystal fractions were in turn systematically recrystallized. The progress of this systematic separation can best be judged by the constants of typical fractions in table 2 . As a result, a portion was isolated which by a final crystallization gave these fractions after removal of propane:

Crystal fraction, $100 \mathrm{ml}, n_{\mathbf{D}}^{25}=1.4297$, $\mathrm{p} p=-112.9_{9}$;

Mother liquor, $\quad 40 \mathrm{ml}, n_{\mathrm{D}}^{25}=1.4295, \mathrm{fp}=-114.4_{0}$.

Because of the similarlity in properties of the mother liquor and the crystal fraction, further purification was deemed impracticable. This crystal fraction is designated in the following section as the "best sample" from petroleum.

TABLE 2.-Data illustrating the rise in boiling point of the crystal fraction with increasing purity ${ }^{1}$

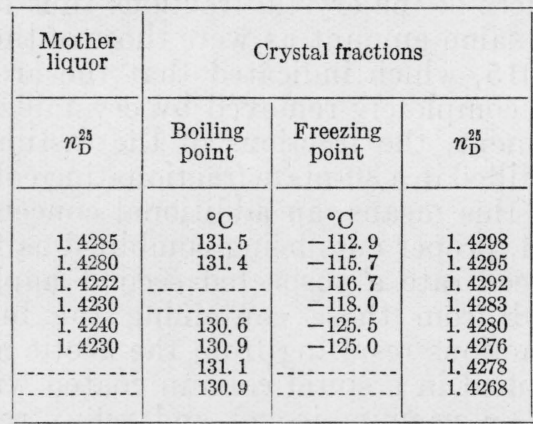

1 The constants in this table are not highly accurate and are to be considered only comparative. The freezing points were determined with a 5 -junction thermocouple in a dewar tube, the boiling points in a Cottrell boiler. 


\section{PROPERTIES AND IDENTIFICATION OF THE ISOLATED ETHYLCYCLOHEXANE}

\section{PREPARATION AND PURIFICATION OF THE SYNTHETIC HYDROCARBON}

The physical properties of the crystal fraction obtained above pointed to its identity as ethylcyclohexane, but because of discrepancies in the values for the physical constants of ethylcyclohexane reported in the literature, it was first necessary to synthesize the hydrocarbon in order to compare its properties with those of the material isolated from petroleum.

A 750-ml lot of ethylbenzen $\mathrm{e}^{13}$ was distilled in a locket-chain column, and a number of fractions, having identical boiling points, and refractive indices were obtained. Freezing curves of the various fractions were taken to establish their purity. The freezing points varied about $0.6^{\circ} \mathrm{C}$, the highest being identical with that of the very pure sample of J. Timmermans ${ }^{14}$ previously tested by the authors. This sample of ethylbenzene was then hydrogenated over a nickelized alumina catalyst after the manner of Zelinsky. ${ }^{15}$

The hydrogenated material $(350 \mathrm{ml})$ was filtered through silica gel to remove the remaining ethylbenzene. As the boiling point of the purified naphthene was thought to be too low, ca. $129.5^{\circ} \mathrm{C}$, it was crystallized once from difluorodichloromethane. (The undiluted liquid partially crystallized on cooling but the mixture was too viscous to be separable.). The crystal fraction now had a boiling point of $130.5^{\circ} \mathrm{C}$ and an initial observed freezing point of $-113.1^{\circ} \mathrm{C} . .^{16}$

Since it has been reported ${ }^{17}$ that methylcyclohexane is formed during the hydrogenation of ethylbenzene, the mother liquor $(90 \mathrm{ml})$ was distilled in a small still. The combined initial fractions had a low refractive index and a boiling point of $126.8^{\circ} \mathrm{C}$. The refractive index of the residue rose slightly (0.0002), indicating a trace of residual aromatics. The large middle portion had a boiling point of $131.8_{5}^{\circ} \mathrm{C}$, as determined in a Cottrell apparatus, and on freezing exhibited the behavior of a very pure substance. It is designated in table 3 as "synthetic." Its freezing curve ${ }^{18}$ is shown in figure 2. The crystal fraction was similarly distilled until 25 percent was taken off. This portion had a low boiling point. The remaining 75 percent, though not as pure as the distilled mother liquor, showed a higher freezing point, $-111.5_{9}^{\circ} \mathrm{C}$, than before distillation.

\section{PROPERTIES OF THE MATERIAL ISOLATED FROM PETROLEUM}

As pointed out in the previous section, the virtual limit of separation by crystallization had been reached for the "best sample" from petroleum. Owing to the difficulties attendant upon the additional preparation of concentrates of material to such a degree of purity, ${ }^{19}$

${ }_{13}$ This was obtained through the courtesy of the George Washington University. It was synthesized by students using the Friedel-Crafts method.

${ }_{14}$ J. Timmermans and F. Martin, J. chim. phys. 23, 758-759 (1926).

15 N. Zelinsky and W. Kommarewsky, Ber. deut. chem. Ges. 57, 667 (1924).

16 Measured with a platinum resistance thermometer. See B. J. Mair, BS J. Research 9, 457 (1932) RP482.

17 F. Sabatier and J. B. Senderens, Compt. rend. 132, 1254 (1901).

18 Crystallization was induced by seed crystals produced outside in a small dewar tube and added when the temperature was slightly below the freezing point.

${ }_{19}^{1}$ It should be noted that the sample under consideration constituted the bulk of the purified material. There were, of course, small amounts of mother liquors. 


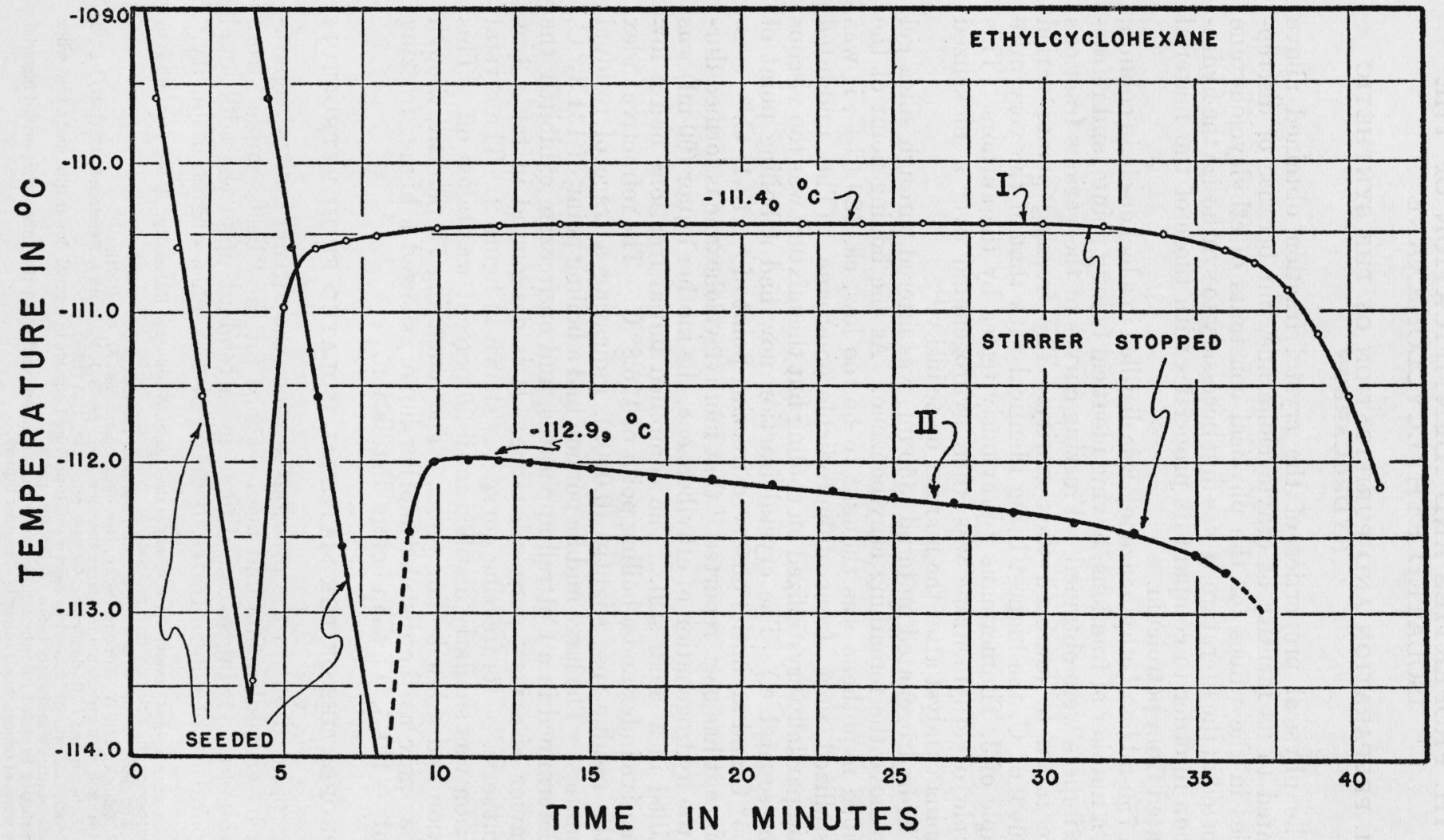

FIGURE 2-Time-temperature cooling curves of synthetic sample, I, and petroleum fraction, II. 
it was decided to examine this material to see if it was a nearly pure substance.

The empirical formula of the hydrocarbon was established by determining the carbon-hydrogen ratio. As a result of two combustion experiments, the mean ratio, moles $\mathrm{H}_{2} \mathrm{O} /$ moles $\mathrm{CO}_{2}$, was found to be $1.0033 \pm 0.0006$. This agrees well with the value for a pure naphthene, $\mathrm{C}_{\mathrm{n}} \mathrm{H}_{2 \mathrm{n}}$, and indicates about 3 -mole percent of impurity if an isononane is the contaminant.

The molecular weight of the isolated material was found to be the same as that of the synthetic ethylcyclohexane by direct comparison of the freezing point lowerings of the two samples in nitrobenzene. This showed the isolated product to be an octonaphthene.

The boiling range of the petroleum sample was determined in the apparatus of Mair. ${ }^{20}$ In distilling $50 \mathrm{ml}$ of a $65-\mathrm{ml}$ sample at the rate of $1 \mathrm{ml}$ per minute, the temperature rose $0.22^{\circ} \mathrm{C}$.

The freezing-point curve is shown in figure 2. The material had a freezing range of $0.5^{\circ} \mathrm{C}$, which indicated that it was approximately pure. This was confirmed by microscopical observation of the liquid during crystallization. ${ }^{21}$ A drop of the material between 2 microscope coverglasses was placed in the dewar flask, which contained no liquid and was maintained at a temperature slightly below the freezing point. Crystallization was induced by seeding. Owing to the viscosity of the liquid, the crystals grew exceedingly slowly under these conditions and were closely packed together. Crystals suitable for examination were obtained only after partial melting and recrystallization. They were then distinctive in habit, having well defined interfacial angles and an extinction nearly parallel to the long edges. All crystallization occurred within a very narrow temperature interval. Only a few degrees below the freezing point, shrinkage cracks developed in the crystals to an extent that would not have been possible had there been any appreciable amount of residual mother liquor. Although the temperature was carried $25^{\circ} \mathrm{C}$ below the freezing point, no new crystalline phase appeared. A similar examination of the synthetic ethylcyclohexane was made. The entire behavior and form of its crystals were indistinguishable from those of the material isolated from petroleum.

A comparison of the physical properties of the synthetic and the petroleum samples with some values reported in the literature ${ }^{22}$ may be made by referring to table 3 .

20 See footnote 16 .

${ }^{21}$ This examination was made by Charles Proffer Saylor, of this Bureau, in the apparatus described by him. W. H. Smith, C. P. Saylor, and H. J. Wing. BS J. Research 10, 484 (1933) RP544.

${ }_{22}$ Ethylcyclohexane has been synthesized many times with varying results as to the physical properties. For earlier preparations consult Beilstein's Handbuch der organischen Chemie. Other recent preparations are by F. K. Signaigo and P. L. Cramer, J. Am. Chem. Soc. 55, 3331 (1933); and R. Adams and J. R. Marshall, J. Am. Chem. Soc. 50, 1970 (1928). 
TABLE 3.-Comparison of the physical constants of ethylcyclohexane from petroleum with various synthetic preparations

\begin{tabular}{|c|c|c|c|c|c|}
\hline Source & $d_{4}^{20}$ & $n_{\mathrm{D}}^{25}$ & $\begin{array}{l}\text { cst in } \\
\text { aniline }\end{array}$ & $\begin{array}{c}\text { Boiling } \\
\text { point } \\
760 \mathrm{~mm}\end{array}$ & $\begin{array}{l}\text { Freezing } \\
\text { point }\end{array}$ \\
\hline From petroleum ("'best sample") & $\begin{array}{c}\mathrm{g} / \mathrm{ml} \\
0.78573\end{array}$ & d 1.42980 & ${ }^{\circ} \mathrm{C}$ & $\begin{array}{l}{ }^{\circ} \mathrm{C} \\
\text { g } 131.5_{1}\end{array}$ & h i $\stackrel{\circ}{-} \mathrm{C}$ \\
\hline $\begin{array}{l}\text { Synthetic: } \\
\text { Rose and White..... } \\
\text { Timmermans s }\end{array}$ & 0.78804 & d 1.43079 & $-1-2-$ & $\begin{array}{r}\text { g } 131.80 \\
131.8\end{array}$ & $\begin{array}{r}\mathrm{h}-111.40 \\
-128.9\end{array}$ \\
\hline Garner and Evans b........... & .7825 & $\cdot 1.4297$ & 43.8 & 131.6 & \\
\hline
\end{tabular}

a Bul. Soc. Chim. Belg. 36, 503 (1927).

b J. Inst. Petroleum Tech. 18, 751-778 (1932).

- \pm 0.00002 . Determined by the Division of Weights and Measures of this Bureau.

d \pm 0.00005 . Determined on a calibrated Abbe refractometer (Valentine design).

- Calculated from value at $20^{\circ} \mathrm{C}$, using $d n / d t=0.00045$ per ${ }^{\circ} \mathrm{C}$.

1 Aniline point.

$\mathrm{g} \pm 0.05$. Determined in a Cottrell boiling-point apparatus.

h $\pm 0.05^{\circ} \mathrm{C}$. Determined with a platinum-resistance thermometer.

i Initial observed freezing point.

All the boiling points are in good agreement. The difference between the boiling points of the isolated and synthetic hydrocarbons, $0.28^{\circ} \mathrm{C}$, is not large, considering the boiling range of the former.

The difference in the refractive indices, 0.0010 , leads to a similar conclusion, with regard to impurities, as that drawn from the combustion analysis and shows about the same paraffin content.

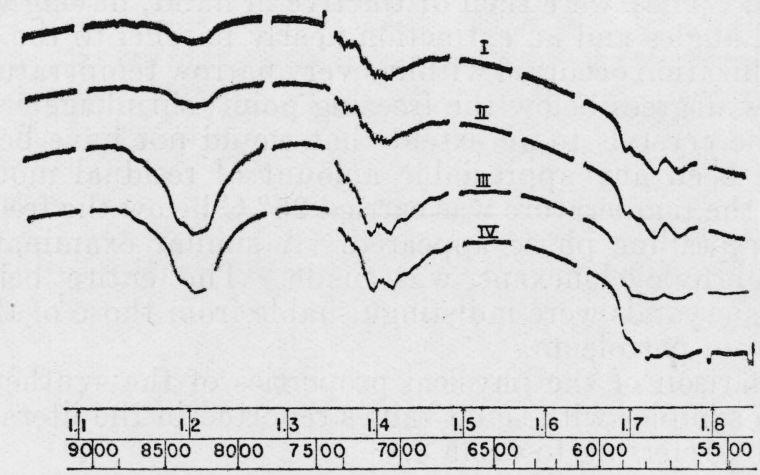

Figure 3.-Infrared absorption curves.

Records of the transmission in the near infrared through 10-cm cell lengths of solutions of the synthetic sample and petroleum fraction of ethylcyclohexane. The solvent was purified carbon tetrachloride and the concentrations were for the synthetic sample, curves II, III, 0.0570 and 0.2974 molal, respectively, and for the petroleum fraction, curves I, IV, 0.0595 and 0.2854 molal, respectively.

In order to give definite proof of the identity of the isolated hydrocarbon, the freezing point of a mixture of $20 \mathrm{ml}$ of the synthetic material and $10 \mathrm{ml}$ of the mother liquor from the final crystallization of the "best sample" was taken. The mother liquor froze $1.3^{\circ}$ $\mathrm{C}$ below the synthetic, and the mixture $0.4^{\circ} \mathrm{C}$ below. Excluding the possibility of two hydrocarbons having nearly the same freezing point and forming a continuous series of solid solutions (a condition found at present only in stereoisomers) this proves the compounds to be identical. 
The infrared absorption spectra of the petroleum and synthetic samples have been recorded by the courtesy of $\mathrm{O}$. R. Wulf and U. Liddel, of the U. S. Bureau of Chemistry and Soils. Both spectra (figure 3) have the characteristics of a substituted cyclohexane, ${ }^{23}$ and their similarity is additional evidence for the identity of the petroleum sample.

The freezing point of the ethylcyclohexane from petroleum is lower than that of the synthetic material by $1.5_{9}^{\circ} \mathrm{C}$. An experimental determination of the cryoscopic constant $\left(K=\Delta t / x_{1}\right.$, where $x_{1}$ is the mole fraction of the solute) by adding pure $n$-nonane to the ethylcyclohexane gave a value of $31^{\circ} \mathrm{C} /$ mole percent. If this value is used, the purity of the "best sample" from petroleum is calculated to be about 95 mole percent.

Because of the fact that the fractions containing the bulk of the ethylcyclohexane were not crystallizable, it was not possible to determine the purity of those fractions and, hence, the amount of ethylcyclohexane from their freezing points (thermal analysis). Moreover, the probable presence of a second napththene makes an estimation of the content by means of refractive index untrustworthy. Therefore, until work on this second component is completed, one can only say that the total content (judged by refractive index) of ethylcyclohexane in this petroleum does not exceed 0.1 percent.

The authors are deeply appreciative of the technical guidance of the late Dr. E. W. Washburn at the inception of this work.

Washington, April 15, 1935.

${ }^{23}$ U. Liddel and C. Kaspar, BS J. Research 11, 599 (1933) RP510. 